\title{
Estimation and Reduction of Methane Emissions at the Scheduled and Repair Outages of Gas-Compressor Units
}

\author{
Alexey V. Strizhenok' ${ }^{1}$ Denis S. Korelskiy ${ }^{1}$ \\ 1 Saint-Petersburg Mining University, Vasilyevsky Island, 21st line 2, 199106, Saint-Petersburg, Russia \\ * Corresponding author's e-mail: alexeystrizhenok@mail.ru
}

\begin{abstract}
Assessment of the negative impact on the components of the natural environment during the scheduled and repair outages of gas-compressor units in transportation the process of the natural gas was the purpose of the performed scientific work. The results of the monitoring studies, in which the methane concentrations were measured in the atmospheric air near the source of pollution and on the border of the sanitary protection zone during volley emissions of natural gas into the atmosphere, are presented in the article. In addition, a method that eliminates the release of the natural gas into the atmosphere during the scheduled and repair outages of gas-compressor units are suggested in the article. The method is based on the redistribution of gas flows and the direction of natural gas to the gas distribution station. Volley emissions of methane into the atmosphere will completely eliminated as a result of implementing this method. The proposed technical solution is aimed at reducing the negative impact on atmospheric air near gas compressor stations. Moreover, the proposed method is able to minimize the economic damage to gas companies because of the loss of marketable products.
\end{abstract}

Keywords: environment, pollution, methane, natural gas, volley emission, compressor station, gas-compressor units, pipelines gas piping.

\section{INTRODUCTION}

The current growth rates of the urban population compel mankind to expand the territory of cities, create industrial agglomerations, as well as build new facilities and buildings for a comfortable existence. It leads to an intensive increase in the demand for fuel and energy resources, which, in turn, leads to an increase in the rates of extraction and transport volumes of basic energy resources.

Nowadays, the natural gas is the most important fuel and energy resource in Russia and in the World. The level of gasification in developed countries reaches $90 \%$, but the quantity of consumed nature gas increases yearly as the population grows and the amount of energy consumed. In this regard, the gas producing countries annually increase the volume of the produced natural gas and the volume of gas exports to developed and developing countries [Makhmudov and Korelskiy 2018].
The constant and uninterrupted supply of gas enables to provide reliable heat and power supply to enterprises and the population in most regions of the country, as well as in countries that are importers of natural gas. This, in turn, serves as a basis for the political and economic stability in Russia and in importing countries.

More than 650 billion cubic meters of natural gas is extracted in Russia annually. According to the Analytical Center under the Government of the Russian Federation, Russia extracted 690.9 billion cubic meters of natural gas in 2017, thus surpassing the quantity of 2016 by $8.1 \%$.

According to the Federal Customs Service of Russia, gas supplies in 2017, including liquefied natural gas, amounted to 210.2 billion $\mathrm{m}^{3}$, an increase of 5.7\% in relation to 2016. Gas in the gaseous state was the bulk of exports, but for the liquefied natural gas it was only 24.4 million cubic meters, that is, slightly more than $1 \%$ [State report 2016]. 
The natural gas is considered to be one of the most environmentally-friendly fuels and energy resources today, but it must be noted that all stages of the extraction, processing, storage and transportation of natural gas are still a source of negative impact on the components of the natural environment, primarily on the atmospheric air. Emissions are characterized by the presence of carbon monoxide (about 28\%), hydrocarbons (about 25\%), nitrogen oxides (about 7\%) and sulfur dioxide (about $5 \%$ ). Only about $20 \%$ of the total amount of substances, emitted into the atmosphere during gas production, is collected and rendered harmless [Beloglazova and Romanova 2017].

The process of natural gas transportation by pipeline transport, in particular gas compressor stations, is one of the most intensive sources of air pollution. A gas compressor station is a complex technical device; therefore, it is necessary to carry out periodic maintenance and repair of gascompressor units and technological equipment during the operation of gas compressor stations in accordance with the technical regulations. The gas-compressor units must undergo temporary outages during the repair work due to the ensuring safety standards. Each outage of the gas-compressor unit is accompanied by the mandatory release of fuel natural gas into the atmosphere. In this regard, the main negative impact on atmospheric air is not on systematic emissions, which are actually small and do not cause significant damage to the natural environment, but rather the volley emissions [Volkodaeva and Kiselev 2017].

Methane is discharged into the atmosphere when gas-compressor units undergo outages (scheduled or repair) at many enterprises. It leads to a sharp increase in the methane concentration within the emission zone. Exceeding the established standards for the concentration of methane in the atmospheric air reaches several tens of times in this area [Beloglazova and Romanova 2017].

Methane emissions occur with high initial pressures (up to 75 kilogram per square centimeters). In the initial period, the speed of methane emission significantly exceeds the speed of sound, and at the end of the emission it is extremely small. A practically pure natural gas without air admixtures is emitted through the source (stand) during the emission period [Userov and Shalbaev 2009].

Currently, there are practically no technological solutions to solve the problem of volley emissions of natural gas into the atmosphere when gas pumping units are out. Such a deficiency in technology has two main components: economic, which consists in the loss of marketable products, and environmental, i.e. pollution of the atmosphere with multiple exceedances of the established normative concentration of methane at the time of gas volley emissions [Townshend and Justice 2002].

\section{MATERIALS AND METHODS}

The main methods of research were: system analysis of fundamental scientific works of Russian and foreign scientists in the field of natural gas transportation and minimization of environmental consequences of this process; environmental monitoring of atmospheric air in the form of field observations of methane concentration during the scheduled and repair outages of gascompressor units; mathematical methods in accordance with the approved methods for calculating the complete dispersion of methane in the atmospheric air; methods of mathematical statistics and cartographic modeling for constructing maps reflecting the ecological situation on the territory of the compressor station location at the moments of volley emissions of natural gas.

Environmental monitoring of the atmospheric air was carried out in accordance with GOST 17.2.4.02-81 «Protection of Nature. Atmosphere. General requirements for methods for determining pollutants» [GOST 17.2.4.02-81]. At the same time, monitoring was carried out not only during the gas volley emission period, but also during the normal operation of the compressor station. These studies confirmed the hypothesis that the main negative impact on the atmospheric air is exerted only in the period of the gascompressor units outage, while during normal operation of the compressor station, the methane concentrations in the air are much lower than the established standard.

Measurement of the methane concentration in the territory of experimental compressor station was carried out by means of the MultiRae Lite portable gas analyzer. The measurement of methane concentration was carried out with a nondispersive infrared sensor (NDIR) in the indicated device, which makes this device reliable, easy to use and highly accurate. The error does not exceed $5 \%$ with a confidence interval of $95 \%$ [Scientific instrument base 2018].

Calculation of methane dispersion in the atmosphere was carried out in accordance with or- 
der of the Ministry of Natural Resources of the Russian Federation of 06.06.2017 №273 «On the approval of methods for calculating the dispersion of emissions of harmful (polluting) substances in the atmosphere» [Order of the Ministry 2018], as well as in accordance with the guidance document RD 52.18.717-2009 «Methodology for calculating the dispersion of pollutants in the atmosphere in case of accidental emissions» [RD 52.18.717-2009].

Simulation of the ecological situation on the territory of the compressor station location and construction of ecological maps was carried out by means of the "Ecolog" software and geographic informational system MapInfo Professional.

The whole scientific instrumental base for carrying out field surveys, mathematical processing of the obtained results and cartographic simulation were given by the Laboratory of Environmental Monitoring of the Saint-Petersburg Mining University [Scientific instrument base 2018].

\section{RESULTS AND DISCUSSION}

Experimental studies were carried out using the example of a single gas compressor station, which is a part of a large gas-main pipeline in the north of Russia. Monitoring studies showed that almost pure methane infiltrates into the atmospheric air during the process of natural gas volley emission, while the flow rate is about 0.7 cubic meters per second in the first minutes of the emission. Thus, the concentration of methane in the immediate vicinity of the source of pollution exceeds the established standard by more than 50 times, and the excess at the border of the sanitary protection zone is about 20 times.

The authors constructed a cartographic model of total methane dispersion in the the atmosphere during gas volley emission (Figure 1) using the methods of mathematical processing and computer simulation. The results of experimental studies carried out by the authors at the object under consideration, were an initial data for the obtained cartographic model. A contrast ratio, which is calculated as the ratio of the current methane concentration in the ambient air to the established standard, was adopted as a parameter for constructing contour lines on the map. All values greater than 1 indicate how many times the current methane concentration exceeds the established standard.
There are practically no technological solutions for minimizing the negative impact of gas volley emissions from gas compressor stations on the atmospheric air in Russia today. The authors have conducted a large-scale literature review and patent search and found an interesting technological solution, which is currently actively used in the storage of oil and gas, namely the gas piping of tanks [Pashkevich and Petrova 2016].

Gas piping of tanks is a system of gas pipelines connecting gas spaces of tanks with a gas collector. The gas collector is a buffer tank, into which vapor of oil products enter when the reservoir is filled. The vapors from the buffer tank return to the reservoirs when the petroleum products are drained. The use of gas piping of tanks allows completely eliminating losses from evaporation when filling reservoirs or draining oil products from reservoirs, as well as during the breathing of tanks due to changes in daily temperatures [Bashkin et al. 2006].

In this connection the development of a gas piping for a compressor station is the most obvious solution to the problem of methane volley emissions into the atmosphere under scheduled and repair outages of gas-compressor units. That allows not only to capture the methane, which is emitted in atmosphere, but also to use it for its own needs, or to return it to the transport cycle.

It is necessary to employ two fundamentally new technological stages at the compressor station to implement the proposed environmental protection measures. The first stage is an additional gas piping that completely eliminates the irrecoverable losses of natural gas in case of scheduled and repair outages of gas-compressor units and directs them to use for own needs or back to the transport cycle after the start of the gas-compressor units. It consists of an additional run of pipelines with smaller diameter, bypassing the compressor station. The natural gas is forcedly discharged in this pipeline in case of scheduled or repair outages of gas-compressor units [Akopova et al. 2013].

The second technological stage is a mobile compressor station that allows the use of natural gas remaining in the section of the pipeline, which is withdrawn from work, for own needs. A mobile compressor station using a direct method of pumping gas from a disconnected section of the pipeline ensures deeper gas evacuation from the gas pipeline, reduces the pumping time and fuel 


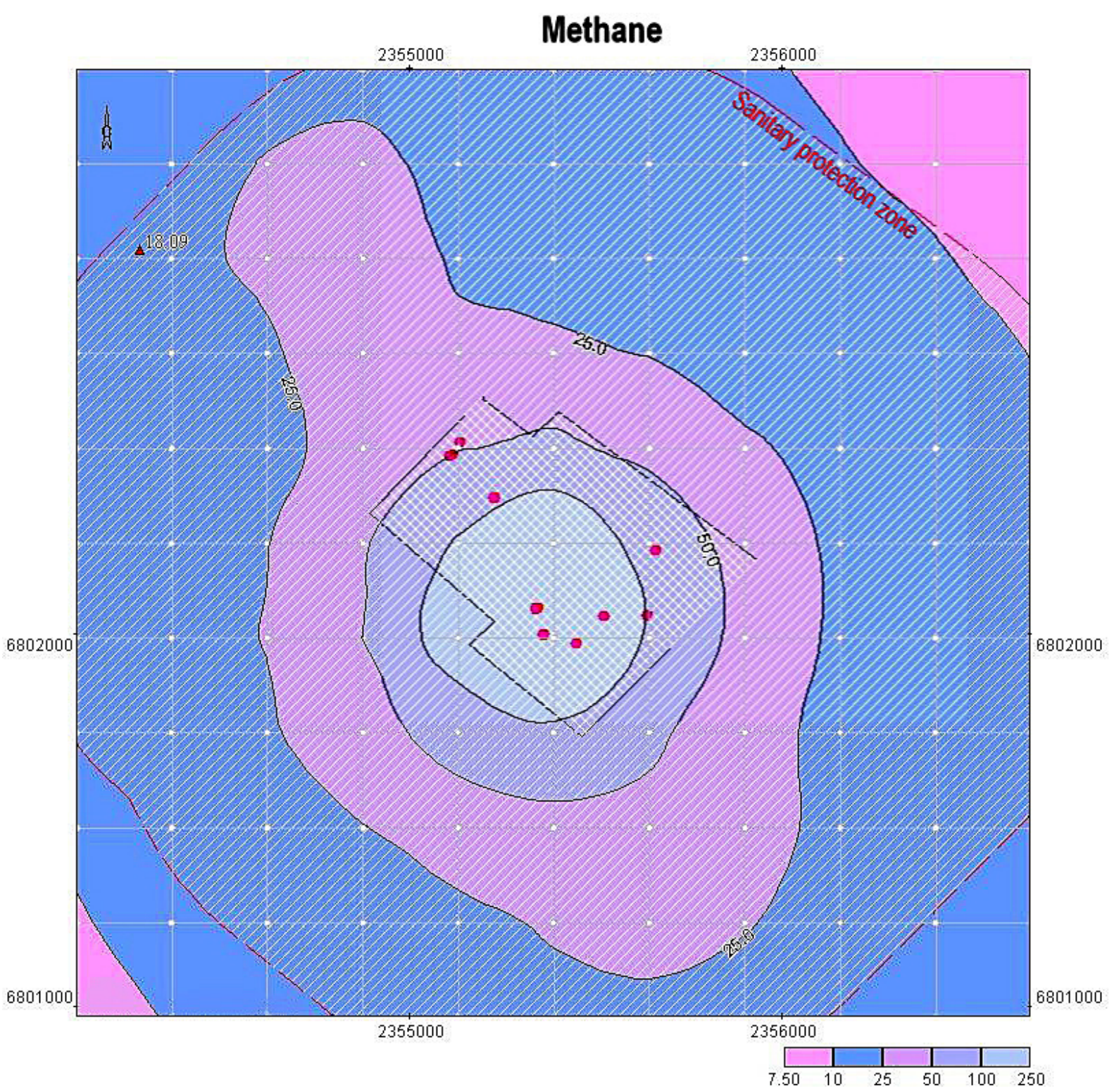

Figure 1. A cartographic model of the total dispersion of methane in the atmosphere during gas volley emission

gas consumption, and also decreases the cost of connecting assembly pipelines to gas pipelines. In addition, a mobile compressor station can be used to organize operational gas supply to remote areas in emergency situations [Jarygin et al. 2008].

Volley emissions of natural gas into the atmosphere are completely excluded at the compressor station after the introduction of the proposed environmental technology. The authors constructed a cartographic model of the total dispersion of methane in the atmosphere during systematic emissions (Figure 2) using the methods of mathematical processing and computer simulation. It reflects the environmental load on the atmospheric air in the vicinity of the compressor station. The map shows that the concentration of methane in the ambient air is below the standard by more than 50 times, and methane emissions into the atmosphere occur only as a result of systematic leaks of natural gas through leakage of flanged connections of gas pumping units and pipelines [Hollingsworth et al. 2008].

The proposed technological solution for the liquidation of volley emissions of natural gas to the atmosphere at compressor stations during the outage of gas-compressor units is economically and technologically justified. The calculation of the environmental and economic efficiency of the proposed action has shown the payback period of less than 1 year. It is possible primarily due to the return to the transport cycle of significant volumes natural gas, which is currently discharged into the atmosphere and cause irreversible damage to the natural environment and the local population. 


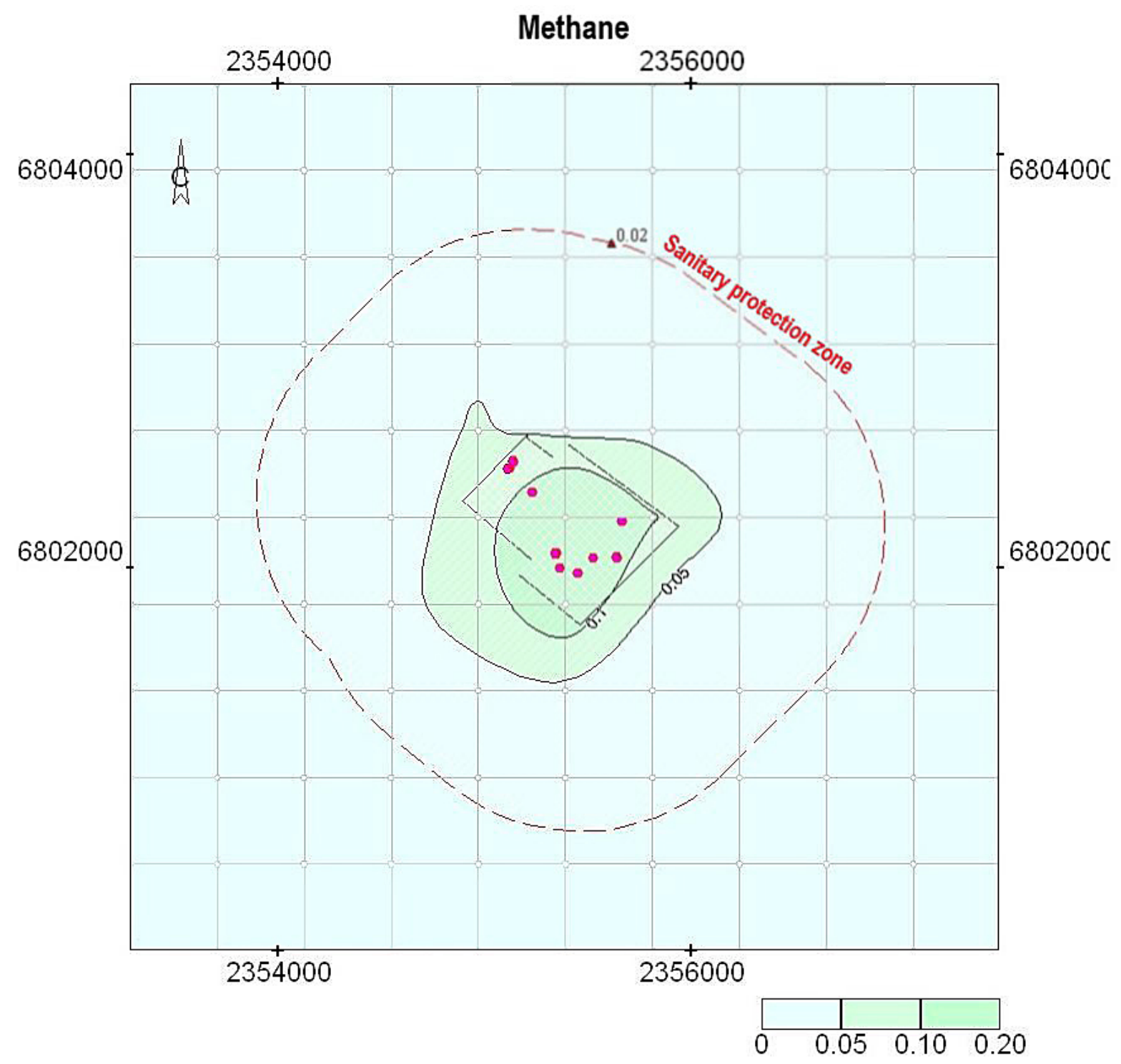

Figure 2. A cartographic model of the total dispersion of methane in the atmosphere during systematic emissions

\section{CONCLUSION}

The natural gas is one of the most promising energy resources today, and the sphere of natural gas production and processing is a developing and promising branch of industry. Like any other production, its insufficient environmental and economic regulation can have a significant negative impact on all components of the natural environment, which will adversely affect the social well-being of the population living in the territory.

A scientific study shows that the natural gas is generally an environmentally-friendly fuel, but there are some stages in the gas industry that still have a high degree of environmental hazard. It can lead to extremely negative economic and social consequences in the territories of hundreds of square kilometers with insufficient environmental protection [Akopova et al. 2013].

The authors proposed a comprehensive system for reducing the anthropogenic load in the scheduled and repair outage of gas-compressor units of compressor stations as part of the scientific study. It is based on the introduction of additional gas piping with further utilization of methane or its return to the transport cycle.

A cartographic model is the fundamental scientific novelty of the study. It reflects the ecological well-being of the territory, exposed to the compressor station of the main gas pipeline during the scheduled or repair outages of gas-compressor units.

The theoretical justification of the gas piping system of the compressor station is the applied 
scientific novelty of the conducted research, as there are no examples of its use in Russia today.

At the same time, the maps of the complete dispersion of methane in the atmosphere before the introduction of the proposed nature protection measures and after its implementation were constructed within the framework of the study. They show that using the pipelines gas piping reduces the methane emissions to the atmosphere to almost zero.

Thus, the implementation of the proposed environmental protection measures is environmentally and economically justified and enables to eliminate the irrecoverable losses of natural gas in the event of gas-pumping units outage, thereby mitigating the volley gas emissions to the atmosphere.

\section{REFERENCES}

1. Akopova G.S., Akopov G.S., Dorokhova E.V., Popov P.B. 2013. Assessment of methane losses with leakage of technological equipment of gas transmission facilities of OAO «Gazprom». Conduct a gas science, 2(13), 43-49.

2. Bashkin V.N., Kazak A.S., Priputina I.V., Gorlov D.V. 2006. Assessment of environmental risk in the modernization of the Central Asia - Center gas pipeline system. Environmental protection in the oil and gas sector, 5, 5-13.

3. Beloglazova T.N., Romanova T.N. 2017. Protection of the atmosphere from emissions during operation of main gas pipelines. The successes of modern natural science, 12, 111-116.

4. GOST 17.2.4.02-81 «Protection of nature. Atmosphere. General requirements for methods for determining pollutants».

5. Hollingsworth A., Engelen R.J., Textor C., Benedetti A., Boucher O. 2008. Toward a monitoring and forecasting system for the atmospheric composition: the GEMS project. Bulletin of the American Meteorological Society, 89(8), 1151-1164.

6. Jarygin G.A., Kantjukov R.R., Fridrik D.E. 2008. Industrial Environmental Monitoring in the Envi- ronmental Management Systems Operated by Gas Transporting Companies. Mining Informational and Analytical Bulletin, 10, 137-144.

7. Makhmudov M.E., Korelskiy D.S. 2018. A technical solution to reduce methane emissions from scheduled and repair outages of gas pumping units. Proceedings of the III International scientific conference "Modern society, global and regional processes", North Charleston, 23-25.

8. Order of the Ministry of Natural Resources of the Russian Federation of 06.06.2017 №273 «On the approval of methods for calculating the dispersion of emissions of harmful (polluting) substances in the atmosphere».

9. Pashkevich M.A., Petrova T.A. 2016. Creation of a system for industrial environmental monitoring in hydrocarbon production and transporting companies of Western Siberia. Journal of Mining Institute, 221, 737-741.

10. RD 52.18.717-2009 «Methodology for calculating the dispersion of pollutants in the atmosphere in case of accidental emissions»».

11. Scientific instrument of the Laboratory of Environmental Monitoring of Saint-Petersburg Mining University. URL: http://old.spmi.ru/system/files/ lib/sci/ckp/ekologicheskoe.pdf (15.07.2018).

12. State report "On condition and protection of the environment of the Russian Federation in 2016". URL: http://www.priroda.ru/upload/ iblock/01a/1.\%20\%D0\%93\%D0\%BE\%D1\%8 $1 \% \mathrm{D} 0 \% \mathrm{~B} 4 \% \mathrm{D} 0 \% \mathrm{BE} \% \mathrm{D} 0 \% \mathrm{BA} \% \mathrm{D} 0 \% \mathrm{BB} \% \mathrm{D}$ $0 \%$ B $\%$ D0 $\%$ B $4 \% 20 \%$ D0\%BF $\%$ D0\%BE $\% 20$ $\%$ D0\%9E\%D0\%9E\%D0\%A 1\%202016.pdf (15.07.2018).

13. Townshend J.R.G., Justice C.O. 2002. Towards operational monitoring of terrestrial systems by moderate-resolution remote sensing. Remote Sensing of Environment, 83(1-2), 351-359.

14. Userov A.G., Shalbaev K.K. 2009. Improving the efficiency of gas pumping units and ways to reduce heat emissions into the environment, Vestnik TarSU, 1, 57-61.

15. Volkodaeva M.V., Kiselev A.V. 2017. On the development of the system for environmental monitoring of atmospheric air quality. Journal of Mining Institute, 227, 589-596. 